\title{
Violências escolares e justiça restaurativa na escola básica estadual de São Paulo na visão dos professores - o papel do diálogo
}

\author{
School violences and restorative justice in the state basic school of São Paulo in the \\ vision of teachers - the role of dialogue
}

Eduardo Santos

Doutor em Educação pela Faculdade de Educação da Universidade de São Paulo. Professorpesquisador do Programa de Pós-Graduação em Educação da Universidade Nove de Julho. São

Paulo - SP - Brasil

edusantos1959@gmail.com

Sara Xavier dos Santos

Mestre em Educação pelo Programa de Pós-Graduação em Educação da Universidade Nove de Julho. Professora de Artes e Supervisora de Ensino na Rede Estadual Paulista de Ensino. São

Paulo - SP - Brasil

sara.xavierdossantos@gmail.com

\begin{abstract}
Resumo: As escolas estaduais paulistas, que compõem a maior rede de ensino do Brasil, vivenciam diariamente atos e fatos de violência envolvendo estudantes com estudantes, estudantes com professores, professores com gestores e gestores com famílias. A tendência é que os impactos dessas ocorrências prejudiquem o ingresso, a permanência e, especialmente, o sucesso da aprendizagem dos estudantes. Em resposta, as autoridades educacionais do estado passaram a implantar programas e projetos para auxiliar no trato de tais violências escolares. Entre eles, a partir de 2010, passa a ser estudada e recomendada a Justiça Restaurativa (JR), implantando-se, em 2016, um projeto-piloto de intervenção, que se mantém atualmente e tem envolvido professores em práticas orientadas por essa abordagem. Tendo em vista que o diálogo constitui instrumento fundante de tal abordagem, neste artigo buscamos responder à seguinte questão de pesquisa: Qual o estatuto teórico do diálogo na implantação da JR, segundo as percepções dos professores das escolas da região da Brasilândia, Zona Norte do município de São Paulo, na prevenção às violências escolares? São analisados, por meio da Análise de Discurso, dados resultantes de sessões de grupo focal realizadas com professores dessa região que se utilizaram da abordagem para intervir nos fatos de violência nas escolas em que atuam. As categorias de análise empregadas foram Violências Escolares, Justiça Restaurativa e Diálogo, baseadas em referencial teórico extraído dos formuladores originais da JR, nas áreas do Direito e da Educação; da produção teórica sobre violência escolar e da estratégia do diálogo proposta por Paulo Freire, ademais de Prandis e Brancher. Os resultados de nossa investigação indicaram que os professores tendem a perceber o diálogo como elemento fundante da Justiça Restaurativa e a validá-lo positivamente nas ações de trato com as violências no ambiente escolar.
\end{abstract}

Palavras-chave: Diálogo. Justiça Restaurativa. Rede Estadual Paulista. Violências Escolares.

Abstract: The state schools of São Paulo, which make up the largest educational network in Brazil, experience daily acts and facts of violence involving students with students, students with teachers, teachers with managers and managers with families. The tendency is that the impacts of these occurrences will impair enrollment, permanence and, especially, student learning success. In response, state education authorities began to implement programs and projects to assist in dealing with such school violence. Among them, from 2010 onwards, Restorative Justice (JR) will be studied and recommended, and a pilot intervention project will 
be implemented in 2016, which is currently maintained and has involved teachers in practices guided by this approach. In view of the fact that dialogue is a fundamental instrument for such an approach, in this article we seek to answer the following research question: What is the theoretical status of the dialogue in the implementation of the JR, according to the perceptions of the teachers of the schools in the region of Brasilândia, Northern Zone of the municipality of São Paulo, in the prevention of school violence? We analyze, through the Discourse Analysis, data resulting from focus group sessions with teachers from that region who used the approach to intervene in the facts of violence in the schools in which they work. The categories of analysis used were School Violence, Restorative Justice and Dialogue, based on a theoretical framework extracted from the original JR formulators, in the areas of Law and Education; the theoretical production on school violence and the dialogue strategy proposed by Paulo Freire, in addition to Prandis and Brancher. The results of our investigation indicated that teachers tend to perceive dialogue as a founding element of Restorative Justice and to validate it positively in actions dealing with violence in the school environment.

Key words: Dialogue. Restorative Justice. School Violence.

\section{Introdução}

A Rede Estadual Paulista, maior rede de ensino do Brasil, atende mais de quatro milhões de alunos, distribuídos em 5,3 mil escolas e diversas etapas e modalidades de ensino: Anos Iniciais e Finais do Ensino Fundamental; Ensino Médio, Educação Especial, Educação de Jovens e Adultos e Educação Profissional. São 230 mil professores e 59 mil servidores, que se reportam às 91 diretorias de ensino, vinculadas à Secretaria da Educação do Estado de São Paulo (SEESP), que servem de apoio às unidades escolares dos 645 munícipios paulistas.

As escolas, que deveriam ofertar acolhimento e aprendizagem, são avassaladas diariamente por violências no ambiente escolar, envolvendo estudantes com estudantes, estudantes com professores, professores e estudantes, professores com gestores e gestores com as famílias. A tendência é que os impactos dessas ocorrências prejudiquem o ingresso, a permanência e, especialmente, o sucesso da aprendizagem dos estudantes. O Registro de Ocorrências Escolares (ROE), plataforma da SEESP, aponta 44.909 casos de conflitos no ano de 2015; 36.945 no ano de 2016 e 37.622 em 2017 nas unidades escolares do estado. Somente na região Norte 1 da cidade de São Paulo, com 103 escolas, foram registrados 1.017 casos de violência nos anos de 2015 a 2017, como posse ou encontro de armas, consumo de álcool e drogas, crimes contra o patrimônio até problemas simples de relacionamento.

Menezes (2013) apontou dados alarmantes sobre as diferentes violências ocorridas no interior das escolas, que vão desde o assédio moral (10\%) à agressão verbal (39\%) e física (5\%). Afirma que $44 \%$ dos professores da rede pública paulista já foram vítimas de algum tipo de violência. Segundo Oliveira (2016), a Procuradoria de Procedimentos Disciplinares contava com um acervo de 6800 processos, grande parte deles oriundos da 
Secretaria Estadual da Educação, tendo ouvido 5.055 pessoas como testemunhas ou indiciadas. Mesmo tendo absolvido $74 \%$ dos servidores que responderam ao procedimento disciplinar, invariavelmente eles são afastados do trabalho para tratamento psicológico após a finalização dos casos.

Embora as relações interpessoais de professores, gestores escolares, funcionários, alunos e seus familiares sejam turbulentas, é possível reconhecer o empenho de cada um dos atores para se inserir adequadamente no modelo de escola que está institucionalizado, com o intuito de realizar a parte que cabe a cada um, sem que, no entanto, isso lhes custe a pouca autonomia que lutaram para conquistar, pois, quando ocorrem violências dentro da escola, atingem a comunidade escolar interna e externa. Os adolescentes, porém especialmente os que estão em conflito com a lei -, se incluem tanto como vítimas quanto como protagonistas de alguma forma de violência dentro e fora dos muros escolares, dado que estão em posição mais frágil em razão das situações de vulnerabilidade constantes a que são submetidos e à sua condição transitória de agressor.

Diante desse cenário, a Secretaria de Estado da Educação de São Paulo vem testando projetos e programas que buscam, se não resolver, minimizar o problema. Entre eles, em 2009 foi lançada a cartilha Normas Gerais de Conduta Escolar do Sistema de Proteção de Proteção Escolar para apoiar as escolas, antes da instituição do projeto na rede pública estadual em 2010, criando a figura do Professor Mediador Escolar e Comunitário (PMEC). Com intuito de subsidiar os mediadores, no ano de 2012 houve a disponibilização do Manual Prático: Introdução à Justiça Restaurativa. No mesmo ano, a Escola de Formação e Aperfeiçoamento dos Professores (EFAP) passou a ofertar cursos online abordando diferentes temas com foco na prevenção de violências, disponíveis para todos os professores e gestores da rede estadual.

Mesmo com essas iniciativas, constantemente outras instâncias são acionadas para interferir em questões simples do cotidiano escolar, sem que isso diminua significativamente o número de ocorrências registradas. Entendemos que, para que tal política alcance os fins desejados - como de resto qualquer política que venha das autoridades educacionais -, ela precisa ser incorporada, em suas concepções e objetivos e em suas estratégias e procedimentos, pelos atores pedagógicos das escolas: professores, gestores, estudantes, ademais de suas famílias.

Uma das respostas adotadas pela Secretaria foi a orientação, a partir de 2014, da abordagem denominada Justiça Restaurativa, criada na esfera do Direito para a busca de 
resolução de conflitos e que passou a ser utilizada, com os mesmos objetivos, no âmbito da educação escolar. Há um projeto de implantação da Justiça Restaurativa em curso na Diretoria de Ensino Norte 1, na região da Brasilândia, uma das mais vulneráveis de São Paulo, sendo essa a selecionada como universo da pesquisa que aqui parcialmente relatamos. A escolha da região se deu em razão dos dados apresentados no Índice Paulista de Vulnerabilidade Social (IPVS) e também por ter uma rede de proteção social (CREAS, CRAS, CAPE, CAPES, Conselho Tutelar, Vara da Infância...) mais atuante, sem a qual seria impossível realizar acordos eficazes, pois os implicados (alunos, professores, gestores escolares, famílias) não possuem conhecimento específico para intervir de forma positiva e propor encaminhamentos que necessitem de um manejo que não é próprio das instituições escolares.

A Justiça Restaurativa, no entanto, não teve aplicação prática sugerida pela SEESP, o que levou essa Diretoria de Ensino a elaborar, em parceria com a Coordenadoria da Infância e Juventude do Estado de São Paulo, um projeto coletivamente, partindo das necessidades apresentadas por profissionais que atuam em escolas desse território. É a esse projeto, especificamente, que se refere o presente artigo.

Embora existam trabalhos sobre a temática da Justiça Restaurativa e ofereçam contribuições valiosas, a maioria dos que resultaram de nossa revisão bibliográfica está focada no campo jurídico e converge ao campo do direito. Encontramos poucas pesquisas na área da educação e nenhuma que tratasse das percepções dos professores sobre o uso da JR como abordagem voltada à prevenção e solução de violências no interior das escolas. Esta pesquisa se justifica, então, por oferecer um prisma diferente, ao se debruçar sobre os registros orais dos professores que estiveram ou estão envolvidos com a aplicação dos procedimentos e da abordagem da JR, isto é, a partir das próprias experiências desses profissionais no processo de implantação da proposta. Para fins deste texto, focamos na análise das percepções dos professores a partir da categoria diálogo, dado que essa é a categoria que representa o instrumento por excelência das práticas prescritas pela JR e que são utilizadas nas escolas. Essa categoria segue definida com base nas sistematizações de Pranis e, em especial, na perspectiva dialógica de Paulo Freire em educação.

Os dados foram coletados segundo a metodologia de Grupo Focal, conforme recomendações de Bernardete Gatti, e consistiu na realização de 3 sessões com professores da região em causa, resultando em dados que foram analisados pela Análise de Discurso, na perspectiva defendida por Orlandi. 


\section{Justiça Restaurativa: origens, princípios e metodologias}

Considerado um dos autores fundantes da Justiça Restaurativa (JR), Zehr (2008) relata que o termo foi utilizado pela primeira vez em 1977, por Albert Eglash, em artigo intitulado Beyond Restitution: Creative Restitution, desde logo estabelecendo as diferenças entre as várias abordagens: nomeia 'justiça retributiva' as sentenças que se baseavam na punição; 'justiça distributiva', as que focavam a reeducação, e 'justiça restaurativa' a que se preocupava com a reparação do dano. O pesquisador buscava demonstrar aos presos como suas ações danosas impactavam negativamente a vida das pessoas atingidas e as possibilidades de reparação dos danos causados. O primeiro movimento da JR iniciou-se para criticar o Estado por ter tomado para si e atribuído a alguns operadores da lei o poder jurídico, focando somente a pessoa que cometeu o crime, sem preocupar-se com a vítima.

O caso da Nova Zelândia é exemplar da busca de uma concepção de justiça que, para ser efetiva no trato de situações de uso de quaisquer tipos de violência, teria de se inscrever no contexto cultural dos povos e das comunidades. É assim que, no país, a JR foi gestada em razão do descontentamento das famílias Maori com a maneira arbitrária como o sistema de justiça e os serviços sociais tratavam os adolescentes dessa etnia que cometiam infrações. Os processos aos quais eram submetidos contrariavam as crenças do povo nativo que, respeitando suas tradições, não isolava um infrator das influências sociais e de sua família por acreditarem que no convívio com os outros membros da comunidade é possível resgatar o que se perde numa relação conflituosa. Para os Maoris, quando alguém comete um erro, é preciso um cuidado maior da comunidade para que a convivência seja reestabelecida. Dada essa insatisfação, um relatório denominado Puao-te-Atutu foi gerado em 1986 e, em 1989, houve a criação da Lei das Crianças, Jovens e suas Famílias. Com a criação da lei, todos os jovens infratores deveriam ser encaminhados para encontros restaurativos com grupos familiares denominados Family Group Conferences. Pranis (2010) relata que o governo da Nova Zelândia aprovou, no ano de 1989, um plano piloto para pôr em prática a Justiça Restaurativa, como forma de atender de modo mais humanizado, primeiro os adultos, posteriormente os adolescentes em conflito com a lei. Inspirados nesse modelo, a partir de 1994 ocorreram os primeiros encontros restaurativos para adultos, facilitados por voluntários. Em 1995 foi fundado o primeiro grupo comunitário de Justiça Restaurativa, usando o mesmo modelo aplicado aos jovens. Inicialmente utilizada dentro do campo criminal, as práticas restaurativas eram realizadas principalmente no Sudeste asiático e no Canadá. 
No Brasil, por ocasião do III Seminário Internacional de Justiça Restaurativa de São Paulo, realizado em 2018, o cônsul-geral do Canadá em São Paulo, Stéphane Larue, recordou que foi na Escola Paulista da Magistratura (EPM), em 2010, que teve início a parceria entre o Brasil e o Canadá em JR, com a realização do Colóquio Internacional Brasil-Canadá - Justiça Restaurativa: práticas do Norte e do Sul. Ele destacou que o governo canadense solicitou a adoção de mais processos restaurativos no sistema de justiça para reduzir a reincidência, principalmente nas comunidades indígenas, lembrando que as estatísticas de 2017 de outros países revelam taxas bastante inferiores de reincidência em grupos sociais que utilizam de práticas restaurativas e concluindo que "Os processos restaurativos com facilitadores treinados são ferramentas poderosas para transformar indivíduos e comunidades, criando uma sociedade mais justa, tolerante, respeitosa, inclusiva e pacífica.” (LARUE, 2018, p.1)

O Conselho Nacional de Justiça elaborou a Resolução 225, de 31 de maio de 2016, dando suporte para os que quisessem aplicar a Justiça Restaurativa no âmbito do Poder Judiciário. Essa Resolução dispõe sobre a Política Nacional de Justiça Restaurativa no Poder Judiciário e dá diretrizes para que os operadores da justiça possam implementar e difundir a prática dessa abordagem. $\mathrm{Na}$ mesma perspectiva, foi elaborado o Provimento n. 35/2014, da Corregedoria Geral da Justiça do Estado de São Paulo, para construir diretrizes legais para a JR. Assim, unificou-se o conceito com base na Resolução 225/16:

\footnotetext{
Art. $1^{\circ}$. A Justiça Restaurativa constitui-se como um conjunto ordenado e sistêmico de princípios, métodos, técnicas e atividades próprias, que visa à conscientização sobre os fatores relacionais, institucionais e sociais motivadores de conflitos e violência, e por meio do qual os conflitos que geram dano, concreto ou abstrato, são solucionados de modo estruturado [...] (SÃ̃O PAULO, 2016)
}

Em conformidade com a Resolução, foram legalmente definidos conceitos como prática restaurativa, procedimento restaurativo, caso, sessão restaurativa e enfoque restaurativo, da seguinte maneira:

I - Prática Restaurativa: forma diferenciada de tratar as situações citadas no caput e incisos deste artigo;

II - Procedimento Restaurativo: conjunto de atividades e etapas a serem promovidas objetivando a composição das situações a que se refere o caput deste artigo;

III - Caso: quaisquer das situações elencadas no caput deste artigo, apresentadas para solução por intermédio de práticas restaurativas; 
IV - Sessão Restaurativa: todo e qualquer encontro, inclusive os preparatórios ou de acompanhamento, entre as pessoas diretamente envolvidas nos fatos a que se refere o caput deste artigo;

V - Enfoque Restaurativo: abordagem diferenciada das situações descritas no caput deste artigo, ou dos contextos a elas relacionados, compreendendo os seguintes elementos: a) participação dos envolvidos, das famílias e das comunidades; b) atenção às necessidades legítimas da vítima e do ofensor; c) reparação dos danos sofridos; d) compartilhamento de responsabilidades e obrigações entre ofensor, vítima, famílias e comunidade para superação das causas e consequências do ocorrido. (SÃO PAULO, 2016)

Nesse contexto, fica claro que a Justiça Restaurativa não substitui a justiça tradicional, podendo ser realizada de forma complementar ou alternativa, na busca de melhores soluções jurídicas para os implicados em cada um dos casos.

Brancher (2008) relata que, no Brasil, ocorreram ações restaurativas desde 2004, buscando outras formas de resolução de conflitos, devido às diferenças e complexidade das diversas violências que acontecem em diferentes contextos sociais. A JR tem sido mais aplicada nos Juizados de Infância e Juventude, mas também nos casos de violência doméstica, processos do tribunal do júri, varas criminais e de execução penal. Vem sendo utilizada como alternativa penal institucionalizada, apoiada pela Associação dos Magistrados Brasileiros e pelo Conselho Nacional de Justiça. Passou a ser considerada, pelo Poder Judiciário, como uma política pública nacional, fundamentada na sistematização teórica de Zehr (2012), que dirigiu o primeiro programa de encontros vítima-ofensor dos Estados Unidos.

Esse autor esclarece que a JR não tem o propósito de trazer reconciliação ou perdão entre vítima e ofensor, tampouco visa a redução ou reincidência dos conflitos. É um modo coletivo de reequilibrar as relações, na forma da convivência possível, a partir do coletivo, lidando com os resultados atuais e futuros da ofensa e suas implicações, envolvendo todos os interessados em solucionar o problema. Ela não se resume a uma técnica, é uma concepção associada a um conjunto de valores. Por não ter uma metodologia própria, pode se valer de procedimentos diversos, desde que haja uma relação dialógica e voluntária na qual vítima, ofensor e comunidade se encontram, com identificação das necessidades de cada uma das partes. Nesse processo, busca-se a reinserção do ofensor na comunidade de origem, após o reconhecimento de seu erro e assunção da responsabilidade pelas consequências do ato cometido, buscando sanear o mal causado. 
Embora o conceito de Justiça Restaurativa ainda esteja em construção, difere da mediação porque todos os envolvidos participam do encontro em busca de um acordo de convivência possível. O facilitador do processo não sugere formas de solucionar a questão, como ocorre na mediação, não se porta como árbitro. Um encontro que se propõe restaurativo permite que o coletivo auxilie a encontrar caminhos e apoie as decisões que a vítima, especialmente, mas também o ofensor, consideram satisfatórios para atender suas necessidades - perdão ou reconciliação não são objetivos primeiros da Justiça Restaurativa. Zehr (2008) afirma ainda que a JR não rebate a justiça formal, apenas usa procedimentos diferentes para tratar a maioria dos crimes e não somente o de menor potencial ofensivo.

A Justiça Restaurativa contraria os pressupostos do sistema de justiça retributiva. Zher (2008) aponta as diferenças entre os dois paradigmas, que sintetizamos parcialmente no Quadro 1.

Quadro 1 - Diferentes visões de justiça

\begin{tabular}{|c|c|}
\hline Lente retributiva & Lente restaurativa \\
\hline A apuração da culpa é central & A solução do problema é central \\
\hline Foco no passado & Foco no futuro \\
\hline Modelo de batalha, adversarial & O diálogo é a norma \\
\hline Enfatiza as diferenças & Busca traços comuns \\
\hline A imposição da dor é a norma & A restauração e a reparação são a norma \\
\hline Um dano social é cumulado ao outro & Enfatiza a reparação de danos sociais \\
\hline $\begin{array}{l}\text { O dano praticado pelo ofensor é contrabalançado pelo dano } \\
\text { imposto ao ofensor }\end{array}$ & $\begin{array}{l}\text { O dano praticado é contrabalançado pela } \\
\text { reparação do mal }\end{array}$ \\
\hline A verdade das vítimas é secundária & $\begin{array}{l}\text { As vítimas têm a oportunidade de dizer a sua } \\
\text { verdade }\end{array}$ \\
\hline O sofrimento das vítimas é ignorado & Reconhece-se o sofrimento das vítimas \\
\hline O Estado age em relação ao ofensor, que é passivo & O ofensor tem participação na solução \\
\hline O Estado monopoliza a reação ao mal cometido & $\begin{array}{l}\text { Vítima, ofensor e comunidade têm papéis a } \\
\text { desempenhar }\end{array}$ \\
\hline O ofensor não tem responsabilidade pela solução & O ofensor tem responsabilidade na solução \\
\hline Os resultados incentivam a irresponsabilidade do ofensor & O comportamento responsável é incentivado \\
\hline Denúncia do ofensor & Denúncia do ato danoso \\
\hline
\end{tabular}




\begin{tabular}{|l|l|}
\hline Enfraquecimento dos laços do ofensor com a comunidade & $\begin{array}{l}\text { Reforço da integração do ofensor com a } \\
\text { comunidade }\end{array}$ \\
\hline O equilíbrio é alcançado rebaixando o ofensor & $\begin{array}{l}\text { O equilíbrio é alcançado soerguendo vítima e } \\
\text { ofensor }\end{array}$ \\
\hline Justiça avaliada por seus propósitos e procedimentos & $\begin{array}{l}\text { A justiça é avaliada por seus frutos ou } \\
\text { resultados }\end{array}$ \\
\hline Ignora-se o relacionamento vítima-ofensor & O relacionamento vítima-ofensor é central \\
\hline Não se estimula o arrependimento e o perdão & Estimula-se o arrependimento e o perdão \\
\hline Procuradores profissionais são os principais atores & $\begin{array}{l}\text { Vítima e ofensor são os principais, com ajuda } \\
\text { profissional }\end{array}$ \\
\hline Valores de competição e individualismo são fomentados & $\begin{array}{l}\text { Valores de reciprocidade e cooperação são } \\
\text { fomentados }\end{array}$ \\
\hline Contextos social, econômico e moral ignorados & Todo o contexto é relevante \\
\hline Presume resultados em que um ganha e outro perde & Possibilita um resultado do tipo ganha-ganha \\
\hline
\end{tabular}

Fonte: Zehr, Howard, 2008.

A Justiça Restaurativa vem sendo muito utilizada no mundo todo, empregada com eficácia em diferentes grupos sociais, mas, devido à conjuntura, teve como foco principal os adolescentes em medidas socioeducativas. No Brasil, já se conhecia a importância do envolvimento da família e seus efeitos benéficos no processo de acompanhamento desse grupo, além da articulação da rede de proteção social e multiprofissional, dando oportunidade de fala e escuta a esses adolescentes. Leoberto Brancher (2008) afirma, sobre a ideia de JR, que ela, ao preocupar-se com diálogo, reparação de danos e assunção de responsabilidade, mesmo sendo praticada em pequena escala, pode abalar as estruturas da justiça formal, que se provou ao longo do tempo e com os resultados auferidos que é um sistema falido, de alto custo social e econômico, não somente para os envolvidos diretamente com o ato violento ou crime, mas para a sociedade e para o Estado. Para ele, a Justiça Retributiva tem foco no ofensor e na lógica punitiva, de acordo com a gravidade do ato cometido, em contraponto à Justiça Restaurativa, cujo foco está em seus valores intrínsecos: respeito, busca de sentido, autonomia, participação e pertencimento. Busca a responsabilização do ofensor diante do dano provocado, mas preocupa-se também com as necessidades advindas do dano causado.

O nome Justiça Restaurativa deve-se à possibilidade de que a justiça possa ser realizada de fato, a partir do contato com o outro e consigo mesmo, reestabelecendo a 
dignidade e o senso de justiça nos participantes; espera-se que ocorra a reparação de danos materiais, mas também dos emocionais. Para tanto, é preciso que haja adesão consciente, repensando-se formas de resolver os conflitos e violências com um novo paradigma. Apoiado nas pesquisas de Zher, Brancher (2008) ratifica a JR como paradigma necessário diante de um mundo caótico, que reforça os diferentes tipos de crime e, em busca de uma resposta rápida, sem reconhecer que cada membro da sociedade é corresponsável por tudo que acontece aos outros membros das diferentes comunidades, promove $\mathrm{O}$ encarceramento em massa, alimentando o ciclo de injustiças e vinganças. No documento intitulado Justiça para o século XXI, ele corrobora as premissas de Zher quando assegura que:

\begin{abstract}
Justiça Restaurativa é um termo genérico para todas as abordagens do delito que buscam ir além da condenação e da punição e abordar as causas e as consequências (pessoais, nos relacionamentos e sociais) das transgressões, por meio de formas que promovam a responsabilidade, a cura e a justiça. A Justiça Restaurativa é uma abordagem colaborativa e pacificadora para a resolução de conflitos e pode ser empregada em uma variedade de situações (familiar, profissional, escolar, no sistema judicial, etc.). Ela pode também usar diferentes formatos para alcançar suas metas, incluindo diálogos entre a vítima e o infrator, "conferências" de grupo de comunidades e familiares, círculos de sentenças, painéis comunitários, e assim por diante. (JUSTIÇA PARA O SÉCULO 21, 2008, p. 04)
\end{abstract}

Valores como justiça, honestidade, cuidado mútuo, responsabilidade e verdade são essenciais para sustentar os acordos que serão estabelecidos no círculo, a partir das histórias contadas e das vivências ofertadas ao outro. Na Justiça Restaurativa, o mais importante não é a metodologia, pois ela transcende fórmulas e métodos. Os valores são determinantes no processo, os espaços utilizados para este fim devem ser cuidados, o sigilo em relação às histórias compartilhadas deve ser mantido. Os processos e as práticas podem ser flexibilizados, mas os valores precisam estar presentes em todos os encontros, para que se tornem sólidos. Essa solidez dos valores e da concepção possibilita que a Justiça Restaurativa possa ser aplicada em diferentes contextos, espaços diversos e comunidades distintas.

A justiça comum falhou não somente no Brasil, mas no mundo todo. Zehr (2008) avalia que a prisão não consegue promover mudança no ofensor ou na sociedade; nomeia o sistema de justiça retributiva de paradigma disfuncional porque não leva em conta as necessidades da vítima e menos ainda as do ofensor. A própria justiça criminal é considerada um sistema de dor, tanto para vítimas quanto para infratores. 
Aportes freirianos: o diálogo como instrumento metodológico da Justiça Restaurativa

O diálogo é entendido por Paulo Freire (1986) como um momento especial no qual a humanidade se estabelece diante do reconhecimento da natureza dos sujeitos e de sua historicidade. Não deve ser visto como uma possibilidade de manipular o outro para conseguir o que se pretende: o encontro com o outro deve possibilitar iluminação, para que, como humanos, a comunhão aconteça. O sujeito consciente do que sabe e do que falta saber, diante da experiência de complementaridade que o outro oferece, pode construir saberes que são necessários para um relacionamento que implica conhecer, criticar e transformar a realidade que se põe diante deles. É a partir do diálogo que se estabelece a relação com a verdade, com a intencionalidade de se fazer compreender pelo outro e de compreender o outro, em busca de uma forma coletiva de libertar-se da opressão. O diálogo ocorre quando a palavra e a ação se alinham, pois "não há palavra sem práxis" (FREIRE 1999, p. 77), não se pode desvincular a ação da reflexão. A palavra somente como expressão da fala, sem sentido, reflexão ou propósito não é diálogo, pois a principal intencionalidade do diálogo é a transformação do mundo.

Nesse sentido, a educação formal é fundamental para o desenvolvimento social e humano. No entanto, conteúdos sem aplicação prática são inócuos, não fazem sentido, não promovem transformação do homem, o qual, transformado pelo saber, poderá transformar o mundo. É no diálogo que se debatem os temas que emergem do contexto dos estudantes, permitindo que se coloquem democraticamente seus pontos de vista e assim desequilibrando a relação de poder representada pela figura do professor ou dos gestores escolares. As relações tecidas na convivência, diante da verdade dita, é uma constante busca de ressignificação de si mesmo, do outro e do mundo. A palavra verdadeira fortalece e humaniza os sujeitos, que interferem no mundo e são afetados por ele em um ciclo constante de palavra-reflexão-ação, como afirma Freire (1999, p. 78):

\footnotetext{
A existência, porque humana, não pode ser muda, silenciosa, nem tampouco pode nutrir-se de falsas palavras, mas de palavras verdadeiras, com que os homens transformam o mundo. Existir, humanamente, é pronunciar o mundo, é modificá-lo. O mundo pronunciado, por sua vez, se volta problematizado aos sujeitos pronunciantes, a exigir deles um novo pronunciar.
}

A reflexão promove liberdade; a partir da consciência da opressão em que vivem, os homens percebem o sofrimento de outros oprimidos, reagem contra a injustiça porque a 
ação libertadora desperta a crença no outro. Para Freire (1999, p.80), conhecer a realidade em que o estudante vive e convive e se aproximar sem medo, sob o compromisso com o que ensina e com "fé na capacidade dos homens" para um diálogo amoroso é essencial na relação professor-aluno, tensionada pela convivência e os saberes que partilham. A relação de poder que se estabelece entre o professor que ensina e prescreve o que o estudante deve saber não se faz em detrimento do estudante que ocupa apenas a posição de aprendiz, sem direto a voz. O convívio entre os dois sujeitos só se faz amistoso pela palavra verdadeira que equaliza a tensão, pelo diálogo (FREIRE, 1999) - e a escola é espaço privilegiado para/do diálogo.

Cabe, no entanto, inserir a comunidade reconhecendo, com humildade, que todos têm saberes a partilhar. Dessa forma, aos processos circulares referenciados por Pranis (2011), com base na abordagem da JR, se alinha a metodologia dos círculos de cultura freirianos, conforme definições do próprio Freire (1996, p. 38):

\begin{abstract}
Os participantes do "círculo de cultura", em diálogo sobre o objeto a ser conhecido e sobre a representação da realidade a ser decodificada, respondem às questões provocadas pelo coordenador do grupo, aprofundando suas leituras do mundo. O debate que surge daí possibilita uma re-leitura da realidade, de que pode resultar o engajamento do alfabetizando em práticas políticas com vista à transformação da sociedade.
\end{abstract}

Os processos circulares propostos por Pranis (2011) guardam forte semelhança com os círculos de cultura freirianos: os participantes se sentam em círculo, simbolizando horizontalidade e igual importância na troca de saberes colaborativos gerados a partir do diálogo e com a intenção de promover conhecimento mútuo; assim como os círculos de cultura têm um facilitador que incentiva a participação de todos os presentes, a partir da 'palavra verdadeira' do respeito, da libertação de si mesmo e do outro, acolhendo diferentes saberes; em ambos os processos há uma busca constante de soluções para as questões do cotidiano e do exercício da cidadania.

Em Medo e ousadia, obra de Shor e Freire (1986, p. 11), os autores explicitam que o diálogo pertence à natureza do ser humano enquanto ser de comunicação. O diálogo sela o ato de aprender, que nunca é individual, embora tenha uma dimensão individual. Freire reafirma que o "diálogo e o questionamento" promovem a aprendizagem verdadeira: pelo diálogo é possível conhecer o que o estudante sabe e o que precisa saber dado o grau de incompletude que demonstra quando a "linguagem autêntica" é apresentada. Assim, recomenda que 
[...] deveríamos entender o "diálogo" não como uma técnica apenas que podemos usar para conseguir obter alguns resultados [ou] como uma tática que usamos para fazer dos alunos nossos amigos. Isto faria do diálogo uma técnica para a manipulação, em vez de iluminação. [...] o diálogo é uma espécie de postura necessária, na medida em que os seres humanos se transformam cada vez mais em seres criticamente comunicativos. O diálogo é o momento em que os humanos se encontram para refletir sobre sua realidade tal como a fazem e re-fazem. (SHOR; FREIRE, 1986, p. 64)

Pranis (2011) em consonância com Freire, assegura que as práticas circulares - que se assemelham aos círculos de cultura - buscam a escuta atenta e amorosa e o respeito mútuos pelos quais todos têm o direito de falar e de ouvir, refletindo sobre o bem-estar coletivo. Denomina a ajuda mútua de sistema de apoio, em que profissionais ou pessoas comuns podem, juntos, se apoiarem mutuamente e servirem de sustentação para o outro em suas necessidades. As práticas circulares são utilizadas com o objetivo de interromper conflitos e animosidades, conferindo relevo às vivências compartilhadas aumentando o senso comunitário ou de interligação entre os envolvidos. Algumas semelhanças que se destacam nos processos dialógicos propostos pelos dois autores e que Freire (1986, p.66) ratifica: a "ausência de autoritarismo, a tensão constante entre autoridade e a liberdade" e o direito a vez e voz, sem que, no entanto, a fala seja obrigatória. No diálogo proposto pelos autores os silêncios também dialogam, a escuta atenta, a observação do todo e do outro constrói possibilidades, destrói resistências e proporciona a liberdade.

Conforme Pranis (2011), as práticas circulares, também denominadas processos circulares ou círculo, apontam para uma forma de conviver baseada nas raízes culturais dos povos ancestrais que tratavam as questões da comunidade de maneira que todos os impactados pelo dano pudessem auxiliar na restauração. Essas tradições ainda persistem e são cultivadas em povos de origem indígena do mundo todo. Essas práticas inspiraram as nossas culturas ocidentais, mesmo as modernas a buscarem outras maneiras de solucionar impasses coletivos, a partir da sabedoria dos povos ancestrais. Os povos nativos de diferentes partes do mundo debatiam as questões da vida e resolviam os conflitos coletivamente. Dessa forma, fortaleciam os laços afetivos com o envolvimento de todos os que eram afetados por ações que provocassem desequilíbrio na comunidade.

No início dos anos 90, as práticas circulares foram levadas para os espaços públicos, num esforço da Justiça Criminal para que seus procedimentos fossem utilizados nas tomadas de decisão coletivas, implicando o causador do dano e a vítima. Os povos do ocidente, diante do encarceramento em massa e da falta de resultados esperados com a forma tradicional de justiça, passaram a utilizar essa forma de resolver conflitos e diversos 
tipos de violência, procurando na sabedoria ancestral que durante milhares de anos sustentou os povos nativos no enfrentamento dos conflitos, respeitando a humanidade do outro. Acrescenta que as práticas circulares priorizam as necessidades de todos os envolvidos em determinado conflito, sejam eles agressor, vítima ou membro da comunidade. Essa metodologia apresenta possibilidades de acordos consensuais, para que a partir deles as pessoas afetadas se sintam compreendidas e respeitadas. Defende o senso comunitário, pois acredita que toda vez que ocorre um conflito ou violência há também um desequilíbrio do qual a comunidade é corresponsável e, como tal, precisa auxiliar na busca da harmonia perdida para que o equilíbrio se reestabeleça, a partir de decisões coletivas que levem à satisfação e boa convivência de todos.

As práticas circulares buscam a escuta atenta e amorosa e o respeito mútuos pelos quais todos têm o direito de falar e de ouvir, refletindo sobre o bem-estar coletivo. São utilizadas em diversos contextos - assistência social, saúde, polícia militar, organizações não governamentais, medidas socioeducativas... - com o objetivo de interromper conflitos e animosidades, conferindo relevo às vivências compartilhadas e, assim, aumentando o senso comunitário ou de interligação entre os envolvidos. Nas escolas são utilizados para dar vez e voz aos estudantes, mas também aos seus familiares, professores, funcionários, com o intuito de solucionar problemas relacionais e evitar que eles evoluam para o status de violência.

Pranis $(2010)$ e Freire $(1986,1999)$ utilizam os mesmos princípios da Comunicação Não Violenta (CNV) elaborada por Marshall B. Rosenberg, PHD em Psicologia Clínica. Ele implantou a metodologia em escolas e universidades que estavam em transição no processo de abandono da segregação racial, no início da década de 1960, lugares em que atuou com arbitragem e treinamento em técnicas comunicativas que foram denominadas comunicação não violenta. $\mathrm{Na}$ contemporaneidade, serve de guia para mais de 65 países nos diversos continentes. A CNV é utilizada em diversos campos de atuação tais como Poder Judiciário, equipamentos policiais e sistemas educacionais. A técnica foi muito usada pelo próprio Rosenberg, nos anos 1990, nas regiões em guerra como Sérvia, Ruanda e Croácia, e também nas escolas de diversos países que usam os círculos restaurativos ${ }^{1}$ para resolução de conflitos. Para o autor, é possível utilizar a abordagem em qualquer segmento, local ou situação em que se estabeleçam relações interpessoais, negociação, desordens e disputas, quer seja nas relações familiares e/ou de amizade, nas instâncias profissionais, no relacionamento afetivo ou quaisquer outras finalidades, pois " $\mathrm{A} C \mathrm{CNV}$ nos ajuda a nos 
ligarmos uns aos outros e a nós mesmos, possibilitando que nossa compaixão natural floresça. Ela nos guia no processo de reformular a maneira pela qual nos expressamos e escutamos os outros [...]" (ROSENBERG, 2006, p. 32).

O autor denomina "comunicação alienante da vida" o uso dos julgamentos moralizantes, pelo qual o sujeito não é considerado, mas apenas o rótulo que carrega. Esse tipo de comunicação impregnada de julgamento demoniza as pessoas, tirando o foco do observador do que realmente importa: o ser humano que está diante dele, com seus valores e suas necessidades.

Tomados em seu conjunto, Freire, Pranis e Rosenberg se alinham preconizando a necessidade das palavras usadas na comunicação para que o diálogo seja estabelecido, mas com o alerta de que a linguagem precisa ultrapassar os limites das palavras e estar permeada de afeto, respeito e empatia.

\section{Técnicas, procedimentos e instrumentos metodológicos}

Os loci de pesquisa foram 5 escolas da região da Brasilândia que permanecem no projeto, aqui nomeadas: Caminho da Sabedoria, Paraíso das Letras, Desejo de Aprender, Alegria do Saber, Caminho da Felicidade nomes fictícios para preservação sigilo.

Optamos pela utilização do grupo focal como instrumento de pesquisa por entendermos que seria a melhor forma de atender aos objetivos do nosso trabalho, uma vez que se constitui como "um bom instrumento de levantamento de dados para as investigações em ciências sociais e humanas [...]” (GAT'TI, 2005, p.8) Para Morgan (1997), pela interação que proporciona, o grupo focal possibilita a coleta de uma grande quantidade de dados em um curto período de tempo. No grupo focal não se espera consenso: é uma representação do contexto social pela qual cada um defende seus pontos de vistas, acata, ratifica ou refuta as opiniões que lhe são apresentadas pelos outros participantes. O grupo focal contribui, entre outras coisas, para que o pesquisador verifique as concordâncias e discordâncias dos colaboradores, o que foi declarado e o que está subentendido, e não exige grandes recursos para sua aplicação. Nesse sentido, o grupo focal se ajustou à nossa pesquisa como instrumento de coleta de dados, pois "há interesse não somente no que as pessoas pensam e expressam, mas também em como elas pensam e por que pensam." (GATTI, 2005, p. 9)

Os sujeitos de nossa pesquisa foram 10 professores atuantes em uma das 5 escolas da região da Brasilândia jurisdicionada à Diretoria de Ensino Norte 1, convidados para 
participar das sessões do grupo focal a partir dos seguintes critérios: participação no Curso de Introdução da Justiça Restaurativa, ministrado pela Coordenadoria da Infância e Juventude, e alguma experiência, mesmo que inicial, na aplicação da JR e/ou da metodologia do Círculo. Os membros do grupo trabalham nas mesmas escolas e foram informados de que a participação era voluntária e que teriam liberdade para se expressar da forma mais conveniente, sem serem criticados por sua posição em relação ao tema abordado. Nomeamos os sujeitos com as letras A, B, C, D, E, F, G, H, I e J, preservando suas identidades.

Orientados por Gatti (2005), buscamos a tematização das questões que servem como guia para o moderador do grupo focal, construindo um roteiro que nos apoiasse na aplicação correta do instrumento de pesquisa. A primeira sessão, de sensibilização e apresentações, trabalhou com a questão norteadora: $O$ que entendem por Justiça Restaurativa? A segunda sessão focou a prática propiciada pela JR e foi balizada pela seguinte questão norteadora: como aplicam a Justiça Restaurativa no espaço escolar? A terceira sessão buscou a análise dos resultados que se podia auferir com as concepções e práticas da JR, exprimindo-se na questão norteadora: Como vocês avaliam os resultados da aplicação da Justiça Restaurativa (prática/teoria)?

Observadas todas as premissas para o desenvolvimento de nossa pesquisa e produção de conhecimento, analisamos os dados na perspectiva de Orlandi (2014), que estabelece a Análise de Discurso como reflexão sobre o lugar do qual se pode observar a relação entre língua e ideologia. Essa técnica questiona a exclusão do fator histórico-social da atividade linguística e as ciências sociais que não aproveitam a materialidade da língua, propondo ligação entre a linguagem e os fatos históricos na criação de outro campo teórico que deve ser desvendado. Os discursos são impactados em diferentes campos do discurso, com suas especificidades histórica e ideologicamente constituídas, que devem ser verificadas à luz da ciência sustentada pela técnica de análise de discurso. Para realizar uma análise de discurso com profundidade que a ciência requer, é necessário buscar os sentidos, o "não dito", o que não está aparente. Orlandi (2014, p. 15) orienta que:

A análise de discurso, como seu próprio nome indica, não trata da língua, não trata da gramática, embora todas essas coisas lhe interessem. Ela trata do discurso. E a palavra discurso, etimologicamente, tem em si a ideia de curso, de percurso, de correr por, de movimento. O discurso é assim palavra em movimento, prática de linguagem [...]. $\mathrm{Na}$ análise de discurso, procura-se compreender a língua fazendo sentido, enquanto trabalho simbólico, parte do trabalho social geral, constitutivo do homem e da sua história. 
A análise de discurso preocupa-se com a linguagem e não com o texto em si; o texto, para Orlandi (2014, p.72), "é uma peça do discurso.” Assim, os textos analisados dão lugar ao processo de compreensão que envolve os sentidos, os significados, e "o produto da análise é a compreensão dos processos de produção de sentidos e da constituição dos sujeitos e suas posições." A técnica de análise do discurso consiste em separar o que é texto do discurso, sendo o primeiro a representação que pode ser escrita e manipulada e o segundo o subjetivo impregnado das vivências, ideologias e práticas sociais. O papel do analista, conforme Orlandi é extrair os sentidos explícitos e ocultos nos discursos dos sujeitos "através do dispositivo analítico" (id.ib.) e, para extrair os sentidos, é preciso separar o real do imaginário. Assim, o objeto discursivo fará sentido diante da mediação do analista.

\section{A restauração do diálogo nas escolas: rompendo o ciclo de violências}

Analisamos os dados coletados nas sessões de grupo focal à luz do problema que desencadeou nossa investigação - as violências escolares -, retomada a partir da questão que anima este artigo, a saber: Qual o estatuto teórico do diálogo na implantação da JR, segundo as percepções dos professores das escolas da região da Brasilândia, na prevenção às violências escolares?

Diante do material coletado foi possível verificar se as concepções e práticas - em especial, o diálogo previsto na metodologia dos círculos - do projeto de Justiça Restaurativa implantado na região da Brasilândia impactam as percepções dos professores quanto ao trato das violências escolares. Buscamos, assim, os sentidos atribuídos pelos professores ao diálogo como instrumento que, incorporado às práticas recomendadas pela $\mathrm{JR}$, repercutem no trato dado às violências no âmbito das escolas.

Aplicou-se o termo violências escolares para denominar os eventos classificados pelas estatísticas da SEESP como conflitos e ocorrências escolares, conforme relatórios de ocorrência lavrados em cada unidade escolar, em alinhamento com a definição de vários teóricos que se alinham no entendimento de que mesmo os atos considerados leves e até mesmo o que não são nomeados estão no campo da violência, pelo fato de infringirem dor, angústia e sofrimento psicológico às vítimas, além da violência física. As violências podem estar presentes e não serem reconhecidas por terem se tornado rotineiras. Nesse contexto, Garcia (2009) aponta o descaso como uma das violências imperceptíveis nas instituições escolares. 
Os sujeitos participantes das sessões do grupo focal se alinham na percepção de que há diferentes violências praticadas na escola, à escola e da escola, como propõe Charlot (2002). Os atos violentos praticados nos arredores da unidade escolar ou na comunidade impactam, direta ou indiretamente, o corpo técnico das unidades escolares, estudantes e suas famílias. A equipe escolar se vê obrigada a administrar ocorrências como uso abusivo de drogas e álcool por parte dos estudantes, violência policial, suicídios, abusos sexuais, entre outros problemas que não apresentam capacitação para manejar.

Em outras questões que se relacionam ao principal objetivo da escola, que é ensinar, os alunos são prejudicados por outras violências, conforme relato de E, que caracteriza a violência simbólica:

\footnotetext{
$\mathrm{Na}$ minha escola é um problema a questão dos pais não concordarem com a reprovação, e quando a gente vai ver o pai tá com toda a razão porque o professor nem tem o registro da nota do aluno no diário, aliás nem preencheu o diário o ano todo e ainda quer ter razão. (Sujeito E)
}

Nesse sentido, Bourdieu (2011, p. 188) esclarece que "O poder simbólico é um poder que aquele que lhe está sujeito dá àquele que o exerce, um crédito com que ele o credita, uma fides, uma auctoritas, que ele lhe confia pondo nele a sua confiança." Tanto os alunos quanto seus familiares entendem que a escola é uma instituição de autoridade, que representa o Estado e, por consequência, o professor está imbuído desta mesma autoridade, pois está a serviço da escola, portanto, a serviço do Estado. Desse modo, os usuários da escola, especialmente da escola pública das periferias, por desconhecerem seus direitos, reafirmam o poder dos professores e da escola retroalimentando o ciclo. Um estudante raramente questiona o resultado das provas, pois embora a legislação vigente destaque seu direito de discordar requerendo nova avaliação e a escola/professor tenham clareza do dever de atendê-lo, na prática isso não ocorre.

As propostas pedagógicas e os regimentos escolares das instituições pesquisadas estão desatualizados, por isso, não preveem o que a legislação determina. $\mathrm{Na}$ análise dos regimentos escolares e das propostas pedagógicas verificou-se que não havia previsão de como seriam executadas as ações que a legislação determina, ratificando a violência simbólica apontada pelo Sujeito E. Os regimentos das instituições pesquisadas preveem transferências compulsórias, suspensões em contraponto à falta de oferta de reforço escolar e compensação de ausências, usando, em alguns casos, os colegiados para a ratificarem suas ações. O fato de os regimentos escolares não indicarem sanções para professores, mas 
somente para estudantes, caso quebrem alguma regra estabelecida, reafirma a violência simbólica.

A CEE 155/17 foi elaborada para proteger os estudantes devido às inúmeras queixas que chegam às ouvidorias da SEESP e Ministério Público de São Paulo, é de fácil compreensão e esclarece de forma didática como as escolas devem agir. Nessa direção, Abramovay (2003, p. 82) considera que

A violência se relaciona com a palavra, assim como com o silenciamento, cerceamento da palavra, em planos diversos. A não negociação de conflitos estimula o recurso da não comunicação. Mas a não palavra se configura em violência além do corte da relação dialógica, a recusa à argumentação, a ouvir e compreender o outro, refletindo e transpondo intolerâncias. A palavra remete também ao lugar da educação, da razão, no debate da violência.

A narrativa de $\mathrm{J}$ também confirma que o comportamento de alguns professores valida a violência institucional, que se torna invisível devido à frequência com que ocorre:

Falta muito para o professor entender o papel dele, ele não tem esse poder que pensa. Julga todo mundo, fala mal dos alunos, do próprio bairro dele. Não são todos, é claro, mas muitos dizem que a escola só tem maconheiro, que é tudo drogado, que a mãe não educa. Discrimina os meninos e pra esses não ensinam nada.

Algumas ações se tornam rotineiras dentro das unidades escolares; para alguns profissionais, especialmente os professores, algumas expressões preconceituosas e discriminatórias estão enraizadas em seus posicionamentos e não dão conta da potencialidade do dano causado aos estudantes. Paulo Freire (1996, p. 16) responde à violência institucional esclarecendo que ensinar exige "rejeição a qualquer forma de discriminação [...] Não é possível pensar os seres humanos longe, sequer, da ética, quanto mais fora dela. Estar longe ou pior, fora da ética, entre nós, mulheres e homens é uma transgressão."

Para o Sujeito D, o problema se agrava quando ganha status de abuso sexual, ao afirmar que "Tem também professor que beija aluna." A violência institucional e simbólica, segundo Charlot (2002), se configura, por exemplo, quando D informa que o professor "que não dá resposta para as perguntas sobre provas. Acha que ele é que tem o poder e os alunos têm que ficar quietinho, como era antigamente."

As percepções dos professores a respeito das violências que estão enraizadas nas escolas, segundo o relato do sujeito E, indicam um tipo de violência que é denominado por Abramoway (2009) negligência e se caracteriza na omissão do responsável - nesse caso, os 
professores - de proporcionar atendimento às necessidades básicas do desenvolvimento dos estudantes. A fala de J: "muitos dizem que a escola só tem maconheiro, que é tudo drogado, que a mãe não educa. Discrimina os meninos e pra esses não ensinam nada", revela o uso da violência psicológica ou agressão emocional, que é tão prejudicial quanto a violência física. Nas palavras dessa autora, os estudantes sofrem porque sentem os reflexos das violências praticadas no espaço escolar, embora algumas dessas violências sejam consideradas de menor potencial como palavrões, apelidos e insultos, e outras vezes sequer chamadas de violência. A autora destaca que os adultos que atuam nas escolas: professores, diretores, agentes escolares são potenciais vítimas, mas também agressores.

A instituição escolar também sofre com os resquícios da violência praticada direta ou indiretamente contra ela. O Sujeito B expressa o sentimento de impotência diante de violências contra as quais não tem energia, autonomia e governabilidade para lutar:

Tem muito caso de violência sexual que acontece lá fora, mas que prejudica a escola por causa da fama e também por causa de a gente não saber como acolher essa vítima da violência na escola. A gente fica em uma encruzilhada, às vezes o diretor não quer que toque no assunto. Tem muito, mas muito mesmo caso de alcoolismo e mais ainda de drogas envolvendo aluno de tudo quanto é tamanho.

Menezes (2013) se alinha com a reflexão que o professor H propõe em seu relato sobre uma violência simbólica, muito comum nas escolas, que é a imposição de regras sem nenhuma discussão com os interessados, os estudantes:

\footnotetext{
Eu acho que a gente cria expectativas em cima do outro, do aluno. E nós ainda queremos aquele aluno, que tem o caderno em ordem, que faz toda lição, que chega no horário, que vem bonitinho, que senta na carteira e fica sentado. Que não te interrompe! E esse aluno não existe mais. O jovem de hoje é outro. $\mathrm{O}$ mundo mudou, a sociedade mudou o jovem mudou e o professor não mudou. - Você tem dificuldade? Eu tenho dificuldade com 23 anos de magistério de encarar isso. E assim a gente não muda. Então eu acho assim, o professor não mudou. Ele está ainda em cima daquele pedestal com a mesma expectativa que a gente tinha lá quando a gente começou a nossa carreira. Então a gente não conseguiu acompanhar a dinâmica desse jovem. O que ele quer da vida, o que que ele quer da escola. E aí, é por isso que surgem os conflitos.
}

Os discursos dos sujeitos confirmam que as escolas, que deveriam ofertar acolhimento e aprendizagem, são submetidas às diferentes manifestações de violência e em diferentes graus, justificando empiricamente o problema que motivou nossa investigação.

A categoria de análise diálogo foi destacada a priori, no processo de revisão de literatura, por permear a maioria dos trabalhos pesquisados, tanto sobre violências escolares 
quanto em relação à Justiça Restaurativa. Os dados resultantes das pesquisas, na forma de estruturas discursivas, agrupam os mais significativos e recorrentes. (cf. Quadro 2)

Quadro 2 - Unidade discursiva: diálogo

\begin{tabular}{|c|c|}
\hline Sujeitos & Estruturas discursivas \\
\hline A & $\begin{array}{l}\text { Essa coisa de você ouvir e o outro te ouvir, eu acho que colaborou bastante para escola. } \\
\text { Porque a gente percebe a necessidade das pessoas. }\end{array}$ \\
\hline B & $\begin{array}{l}\text { Na escola onde eu estou, a punição não parte da gestão. Ela já está trabalhando aos poucos esse } \\
\text { problema usando o diálogo para entender o motivo da ocorrência. A gente já não está mais } \\
\text { punindo. }\end{array}$ \\
\hline $\mathrm{C}$ & $\begin{array}{l}{[\ldots . .] \text { a gente conversa com ele e ela sabe que vai ter que arcar com as consequências, e todos os }} \\
\text { envolvidos, junto com ele }[\ldots . .] \text { ele vai estar ouvindo e, na medida do possível, fazer com que } \\
\text { essa pessoa entenda que há a necessidade da responsabilização por aquele ato praticado. [...] que } \\
\text { ele vai estar com algum problema e que a gente consegue praticar esse diálogo e essa escuta, a } \\
\text { gente vai sempre ter alguma coisa positiva, saindo dali. }\end{array}$ \\
\hline B & $\begin{array}{l}\text { [...] E a partir do momento, que acontece alguma coisa errada, um conflito, uma confusão e, a } \\
\text { Justiça Restaurativa é usada, a gente abre a escuta para os dois lados, sem interferir nas } \\
\text { conversas, mas dando cada um sua sugestão para resolver o problema. }\end{array}$ \\
\hline $\mathbf{H}$ & $\begin{array}{l}\text { [...] Outra coisa que a Justiça Restaurativa, também nos ajudou muito, é que, como professora } \\
\text { mediadora, foi no trato com os familiares, com as famílias dos alunos. A gente começa a trazê- } \\
\text { los pra escola e eles começam a perceber que você está ali, disposta a escutar os "n" problemas } \\
\text { deles. E saem felizes, porque, muitas vezes, eles falam assim: } \\
\text { "Nossa, nessa escola tem alguém que me escute. Porque antigamente, ninguém } \\
\text { escutava a gente aqui nessa escola. Agora sim, vocês escutam". }\end{array}$ \\
\hline F & $\begin{array}{l}\text { É legal ouvir, por exemplo a "H" falar essa questão do professor, porque eu me coloco no lugar } \\
\text { do professor, olhando pra "H" em alguns momentos, a gente falava assim: } \\
\text { "Nossa, ela só passa a mão na cabeça dos alunos". } \\
\text { - Porque esse processo do diálogo, já vem aqui no (nome da escola) a muitos anos, } \\
\text { porque a "H" é uma pessoa, que ela não é a favor da punicão. Ela é a favor do diálogo. Então a } \\
\text { muitos anos ela diz "conversa". E eu ouvi muito (e inclusive eu falei): } \\
\text { "Ó lá! Só passando a mão na cabeça de novo. Ó! aprontou, vai passar a mão na } \\
\text { cabeça". }\end{array}$ \\
\hline A & $\begin{array}{l}\text { - E você não julgar e ele perceber que você pode falar. E ao mesmo tempo, ele percebe } \\
\text { que, de repente, aquilo que ele falou, tem de ouvir de vez em quando, que não foi tão bacana }\end{array}$ \\
\hline $\mathbf{A}$ & $\begin{array}{l}\text { [...] porque a justiça me trouxe isso, de você ouvir tranquilamente a pessoa e deixar ela falar. } \\
\text { Porque ela precisa daquilo, porque no íntimo dela, aquilo é verdadeiro, é fato. Então eu acho } \\
\text { que, se alguém chega lá: } \\
\text { "O que a gente vai fazer nesse círculo?"... } \\
\text { "A gente vai conversar de verdade". } \\
\text { - A gente vai conversar com liberdade. Eu vou só ouvir, eu não vou falar nada. Então } \\
\text { eu acho que isso é importante. }\end{array}$ \\
\hline
\end{tabular}

Fonte: Elaboração própria.

As falas dos sujeitos indicam que o Círculo proporciona que os estudantes tenham a oportunidade de "você ouvir tranquilamente a pessoa e deixar ela falar" (Sujeito A), em um lugar seguro. Quando, segundo A, os alunos utilizam a expressão "a gente vai conversar de verdade", parecem estar expressando que em outras ocasiões a conversa foi 
superficial ou que os envolvidos no suposto diálogo não queriam de fato ouvir e falar com atenção, permitindo que cada um dissesse o que pensava sem o risco de serem ignorados ou mal interpretados.

Nesse sentido, "muitos acreditam que diálogo é uma espécie de questionário, onde um pergunta e o outro responde.” (FREIRE, 1995, p. 32) É muito comum esse 'diálogo' nas escolas: diante da urgência de resolver uma questão, o profissional pergunta ao estudante o que aconteceu, determina imediatamente que 'não foi nada' e pede que os alunos retornem para a sala de aula. Os sujeitos B e $\mathrm{H}$ declaram que as partes precisam estar dispostas a escutar e se comprometer a encontrar, juntas, uma solução para o problema. O Sujeito F afirma que uma das dificuldades é a aceitação de alguns professores, que esperam que haja punição exemplar para os alunos que se envolvem em algum tipo de violência e que os demais, por medo, não repitam o mesmo comportamento. Revela que alguns docentes entendem que o diálogo, que dá espaço para que os estudantes se manifestem, configura uma conivência do profissional que os 'atende', desconsiderando o que Freire (1995, p. 1995, p. 43) declara:

\footnotetext{
o verdadeiro diálogo não pode existir se os que dialogam não se comprometem com o pensamento crítico; pensamento que, não aceitando a dicotomia mundohomens, reconhece entre eles uma inquebrantável solidariedade; pensamento que percebe a realidade como um processo de evolução, de transformação, e não como uma entidade estática; pensamento que não se separa da ação, mas que se submerge, sem cessar, na temporalidade, sem medo dos riscos.
}

Um diálogo franco com os estudantes em que haja espaço para, inclusive, discordarem dos adultos, pode fortalecer as relações, mostrar que há uma outra forma de resolver conflitos corriqueiros sem que ganhem uma proporção desnecessária e diferentes manifestações de violência. Se o estudante conseguir vislumbrar outras maneiras de convivência, poderá usar o poder de reivindicação, ao invés do confronto, o que confirmará que "A esperança é o motor silencioso, conduzindo o poder pessoal em um sentido positivo." (PRANIS, 2011, p. 31)

Rosenberg (2006) apresenta subsídios para uma comunicação não violenta que pode auxiliar nos momentos em que as violências se manifestam, um tipo de comunicação amorosa e empática que ajuda a baixar a ansiedade e acalmar os ânimos dos envolvidos. Os dados não apontaram indícios de que essa forma de comunicação tenha sido utilizada pelos sujeitos, mesmo durante a aplicação da técnica do Círculo. 
Diante dos dados analisados, pode-se apresentar uma avaliação mais geral de que o processo de implantação da JR na rede estadual, no caso das escolas de Brasilândia, tem sido positivo, mesmo atingindo parcialmente seus objetivos. Cabem, no entanto, algumas observações críticas para a continuidade da JR sobre:

a) Dimensão relacional - os dados apontaram que a relação entre professores que fizeram o curso e os estudantes melhorou, a partir da escuta atenta e, por vezes, afetiva dos docentes, mesmo quando não realizavam os círculos de construção de paz. Ao ouvirem as histórias dos alunos passaram a compreender melhor a problemática que envolvia os estudantes, suas famílias e, especialmente, as instituições no processo de acolhimento dos adolescentes, facilitando sua permanência na escola.

b) Dimensão institucional - esse eixo ainda não foi atingido, pelo pouco tempo de aplicação do projeto, mas também devido às amarras institucionais que dificultam o enraizamento das ações ao invés de auxílio e sustentação. Regimentos escolares e propostas pedagógicas das escolas envolvidas na pesquisa não refletem as concepções da Justiça Restaurativa, sequer mencionam o processo circular como metodologia para prevenção e resolução coletiva das ações de violência. Quatro das cinco escolas envolvidas na pesquisa ainda mantêm em seus regimentos escolares, de forma implícita ou explícita, expressões que apontam para a punição e que preveem sanções como suspensão, transferência acordada, transferência compulsória, afastamento dos alunos das aulas. Em última análise, nenhuma delas prevê, quando uma das sanções é levada a efeito, quais seriam as garantias que os alunos teriam quanto ao acesso aos conteúdos, compensação das ausências e reforço escolar. As escolas se inspiraram no documento oficial da Secretaria da Educação do Estado de São Paulo, a cartilha Normas Gerais de Conduta Escolar - Sistema de Proteção Escolar, lançada em 2009, embora a SEESP já tenha recolhido o material e ratificado que esses procedimentos são ilegais. As propostas pedagógicas das escolas também não estão alinhadas com os regimentos escolares, isto é, os dois documentos se apresentam de forma independente sem atender ao que a legislação determina. 
c) Dimensão pessoal - as expressões: "eu penso na minha vida", "como eu fiz isso!", "eu tenho que encarar", "que trabalho eu posso fazer com isso", utilizadas pelo Sujeito A; as reflexões indicadas na fala do Sujeito F, quando diz "eu percebo que se torna uma filosofia de vida", e também os apontamentos do sujeito D: "É pra todos e todos os cursos que eu fiz, posso dizer que esse foi o único que eu levo pra minha vida", todas essas manifestações indicam que a formação inicial e a aplicação dos círculos, na prática, proporcionou a eles oportunidade de refletir sobre o que aprenderam e gerou uma reflexão inicial que pode favorecer outras descobertas sobre si mesmos.

No entanto, ainda é preciso que os gestores das escolas loci da pesquisa atentem para o viés institucional, revendo democrática e coletivamente seus regimentos escolares e propostas pedagógicas para fortalecer as ações que se iniciaram, movimento sem o qual o trabalho fica inviável a médio e longo prazos. Nesse contexto, entendemos que a multiplicação das aprendizagens e a replicação do projeto são elementos fortemente contributivos para que outros atores se juntem aos que iniciaram o trabalho, garantido a longevidade das ações, especialmente tendo em vista a alta rotatividade dos profissionais e as violências a que professores, funcionários, alunos e seus familiares estão submetidos diariamente.

A análise dos dados demonstrou que os professores agem, às vezes, com firmeza, outras vezes, apresentam fragilidade de iniciante no processo de incorporação tanto dos princípios e valores da abordagem da Justiça Restaurativa quanto da aplicação da metodologia dos círculos, sugerida como uma das opções para conseguir maior eficácia na aplicação da abordagem. Os discursos dos professores sugerem que a JR pode ser um meio de acolher as necessidades de pertencimento, nomeado "sentimento de pertença" por Kay Pranis (2010). Ouvir o que professores, gestores, pais, funcionários e, particularmente, os estudantes têm a dizer, acolhendo suas angústias, desejos, medos, frustrações, críticas e sugestões, com escuta amorosa, dispostos a abrir mão do poder sobre o outro para partilhar o poder pessoal com o outro, pode mudar as relações dentro das instituições escolares e prevenir e/ou amenizar as manifestações das violências escolares.

Tal situação, tendo em vista as falas aqui analisadas, parece-nos deixar claro que todos os sujeitos envolvidos no labor pedagógico escolar, se efetivamente querem propor 
convivência pacífica e positiva para todos, estão irremediavelmente constrangidos ao diálogo.

\section{Considerações Finais}

Determinamos como nosso objetivo específico compreender as percepções dos professores da região da Brasilândia sobre o estatuto da categoria diálogo no processo de resolução (e/ou prevenção) de fatos e atos violentos na escola, para então avaliar qual a efetividade da abordagem (concepção e metodologia) denominada Justiça Restaurativa na prática docente.

O processo de implantação da JR na região de Brasilândia é recente, porém, há fortes indícios de que as suas diretrizes estão sendo assimiladas pelas escolas Caminho da Sabedoria, Paraíso da Letras, Inovação, Alegria do Saber e Caminho da Felicidade. A escola Desejo de Aprender apresentou encaminhamento equivocado acerca de um caso com o uso do celular, mas deu indicações de estar buscando formas de prevenção às violências que não, simplesmente, culpabilizem os estudantes.

Quanto aos procedimentos circulares, a análise dos discursos mostrou que há tentativas esporádicas de uso da metodologia, posto que ela começa a ser reconhecida pelos professores como valioso instrumento de prevenção e manejo das violências escolares. Embora a expressão Comunicação Não Violenta não tenha sido citada por nenhum dos participantes, sugere apenas que os profissionais não estão nomeando a técnica, porém fica claro, em seus discursos, que utilizam formas de diálogo similares às sugeridas por Marshal Rosenberg (2006) quando descrevem sua atuação no círculo ou a maneira cuidadosa com a qual se dirigem aos estudantes e suas famílias. Da mesma forma, ainda que intuitivamente, indicam que a estratégia do diálogo se mostra como a mais fecunda para o trato das violências escolares.

No entanto, importa dizer que as dificuldades que aparecem nos discursos dos participantes do grupo focal se referem, especialmente, à resistência dos professores diante de novos princípios e novas formas de atuar com as violências que ocorrem nas escolas e no entendimento equivocado da equipe escolar quando o facilitador utiliza o diálogo como principal ferramenta para compreender o que desencadeou a ação violenta. Essas resistências e equívocos de entendimento podem ser minimizados se houver ampla e constante discussão com e entre equipe pedagógica, alunos e famílias, num processo de fomento à participação ativa de todos esses sujeitos na elaboração e divulgação dos 
instrumentos institucionais, em especial o Regimento Escolar e o Projeto PolíticoPedagógico das escolas.

Os dados coletados confirmaram que as percepções dos professores sobre Justiça Restaurativa se alinham, em larga medida, com os princípios e valores que essa abordagem propõe, auxiliando no manejo das violências escolares, provocando reflexões sobre a cultura punitiva e suas consequências na vida dos estudantes e suas famílias. Os dados também demonstram que a partir da JR os professores conheceram ou estreitaram as relações com a rede de proteção social, garantindo aos estudantes outros direitos para além do direito subjetivo à educação tais como: saúde mental, tratamento médico e acompanhamento do Conselho Tutelar para sugerir possibilidades de convivência familiar.

Muitas violências que ocorrem nas escolas, sejam as que se atribuem a gestores, professores e estudantes sejam as que envolvem seus familiares, poderiam ser prevenidas ou ter seus impactos amenizados se a legislação vigente fosse cumprida. Existem inúmeras normas determinando a forma correta de execução dos atos escolares de acolhimento, de garantia do direito subjetivo à educação, de ingresso e permanência dos estudantes na escola. Mesmo assim, as equipes escolares cometem violências que sequer são entendidas como tal, e poderiam ser evitadas. Parte das chamadas irregularidades é cometida por desconhecimento da legislação, que impõe que ao supervisor de rotina e à Diretoria de Ensino compete auxiliar as equipes a partir de pautas formativas para serem discutidas democraticamente durante a Hora de Trabalho Pedagógico Coletivo (ATPC).

Advogamos, com base na pesquisa parcialmente retratada neste artigo, políticas públicas que enfrentem as violências escolares com a seriedade que o problema requer. Para que isso ocorra são necessárias pesquisas com levantamento de dados do 'chão' da escola. É preciso nomear as violências como elas são, sem o verniz das expressões 'conflito' ou 'ocorrência' que amenizam a questão, fragilizam profissionais da educação e estudantes e não promovem insumos para políticas públicas eficazes. E cabe privilegiar o diálogo como matéria-prima fundamental das relações sociais escolares.

Os relatos dos professores apontam para a necessidade de as instituições tratarem o tema violência com seriedade, procurando estratégias para amenizar os impactos de suas manifestações nas escolas. Os órgãos governamentais, especialmente na instância estadual, precisam focar na prevenção primária para que situações como as apontadas pelos professores não ocorram nas escolas. E a disposição permanente para o diálogo, entendido como ferramenta mais humana existente para dar curso a relações sociais positivas e 
pacíficas, é o instrumento estratégico que está à disposição das equipes pedagógicas, destarte todos os problemas de violência social que invadem as escolas e da burocratização político-administrava que as paralisa.

Aliás, diante de tantas violências, iniciativas como a Justiça Restaurativa e as técnicas dos círculos devem ser utilizados permanentemente, não somente para tratar das consequências das violências escolares, mas também como estratégia de prevenção, para tanto cabendo estar prevista no Projeto Político Pedagógico e no Regimento Escolar. A realização de círculos de acolhimento, discussão e celebração com diferentes grupos de estudantes, familiares, professores, funcionários e equipe gestora, para discutir livremente temas que estão presentes no cotidiano e são desencadeadores de violências, podem colaborar para o estreitamento das relações e alinhamento das ações, servindo como prevenção e preparando a escola para a realização de círculos de resolução de violências, quando elas ocorrerem.

\section{Referências}

ABRAMOVAY, M. Violência nas escolas. Brasília: UNESCO, 2002.

ABRAMOVAY, M. Cotidiano das escolas: entre violências, Brasília: UNESCO, Observatório de Violência, Ministério da Educação, 2005. 404 p.

ABRAMOVAY, M. Violências nas escolas: versão resumida. Brasília: UNESCO, 2003. Disponível em: https://unesdoc.unesco.org/ark:/48223/pf0000145265. Acesso em: 10 março de 2018.

ABRAMOVAY, M. (org). Violência nas escolas: situação e perspectiva. Boletim 21, Brasília/DF, 2005.

APEOESP. Observatório da Violência. Disponível em: http://www.apeoesp.org. $\mathrm{br} /$ publicacoes/observatorio-da-violencia. Acessado em 20/07/2016.

BOYES-WATSON, C.; PRANIS, K. No coração da esperança: guia de práticas circulares. [Projeto] Justiça para o século 21: Instituindo Práticas Restaurativas. Porto Alegre: AJURIS. Brasil. Brasil, 2011.

BOURDIEU, P. O poder simbólico. 15. ed. Rio de Janeiro: Bertrand Brasil, 2011.

BRANCHER, L. (2008). Iniciação em Justiça Restaurativa: formação de lideranças para a transformação de conflitos. [Projeto] Justiça para o Século 21: Instituindo Práticas Restaurativas. Porto Alegre: AJURIS.

BRASIL. Constituição (1988). Constituição da República Federativa do Brasil. Brasília, DF, Senado, 1998. 
BRASIL. Parâmetros Curriculares Nacionais. Temas transversais. Brasília: MEC/ SEF, 1998.

BRASIL. LEI No 9.394 - Estabelece as diretrizes e bases da educação nacional. Brasília, DF Senado, 1996.

CHARLOT, B. Violência nas escolas: como os sociólogos franceses abordam essa questão. Sociologias, Porto Alegre, n. 8, jul./dez. 2002, p. 432-443. Disponível em $<$ http/www.scielo.br $>$. Acesso em: 20/setembro/2018

FREIRE, Paulo. Pedagogia da autonomia: saberes necessários à prática educativa. São Paulo: Paz e Terra, 1996.

FREIRE, Paulo. Pedagogia do Oprimido. 17. ed. Rio de Janeiro: Paz e Terra, 1987. 92

FREIRE, Paulo. Pedagogia da Autonomia: Saberes necessários à prática educativa. São Paulo: Paz e Terra, 1999.

GATTI, B. A. Grupo focal na pesquisa em Ciências Sociais e Humanas. Brasília: Liber Editora, 2005.

IBGE - Instituto Brasileiro de Geografia e estatística. Indicadores Sociais municipais, 2010 Disponível em < http://www.iprs.seade.gov.br/ipvs2010/view/pdf/ipvs/estado.pdf>. Acsesso em 02/01/18.

MENEZES, Lívia. Violência escolar: o professor sob ameaça. Folha Dirigida, out. 2013. Disponível em: < www.apeoesp.org.br/d/sistema/publicacoes/571/arquivo/pagina16.pdf $>$

ORLANDI, Eni Puccinelli. Análise de Discurso - princípios \& procedimentos. Campinas, SP: Pontes, 2014.

PRANIS, Kay. Processos Circulares. São Paulo: Palas Athena, 2010.

ROSENBERG, Marshal, B. Comunicação Não Violenta: técnicas para aprimorar relacionamentos pessoais e profissionais. 4 ed. São Paulo: Ágora, 2006.

SÃO PAULO (ESTADO). Centro de Apoio Operacional Cível e de Tutela Coletiva do Ministério Público do Estado de São Paulo. Área: educação, Curso de Introdução à Justiça Restaurativa para Professores Mediadores Escolares e Comunitários, 2012.

SÃO PAULO (Estado). Resolução SE n. 19, de 12-2-2010. Instituiu o Sistema de Proteção Escolar na rede estadual de ensino de São Paulo e criou a função do Professor-Mediador Escolar e Comunitário, para implementar as respectivas ações especificas. Diário Oficial Poder Executivo, Seção I, São Paulo, 120 (30), p. 29.

SÃO PAULO (Estado). Resolução SE n. 7, de 19-1-2012. Dispõe sobre o exercício das atribuições de Professor Mediador Escolar e Comunitário do Sistema de Proteção Escolar, e dá outras providências. Diário oficial Poder Executivo, Seção I, São Paulo, 122, p. 14. 
SÃO PAULO. Resolução SE 2, de 06 -1-17. Altera a Resolução SE 19, de 12.2.2010, que institui o Sistema de Proteção Escolar na rede estadual de ensino de São Paulo, a Resolução SE 7, de 19.1.2012, que dispõe sobre o exercício das atribuições de Professor Mediador Escolar e Comunitário do Sistema de Proteção Escolar e a Resolução SE 53, de 22.9.2016, que dispõe sobre a consolidação das normas que regulam e regulamentam o Programa Escola da Família - PEF, nas escolas da rede pública estadual, e dá outras providências. (REVOGADA).

SÃO PAULO. Resolução SE 41, de 22-9-2017. Institui o Projeto Mediação Escolar e Comunitária, na rede estadual de ensino de São Paulo, e dá providências correlatas (REVOGADA, EXCETO CAPUT DO ARTIGO $1^{\circ}$ )

SÃO PAULO. Resolução SE 8, de 31-1-2018. Dispõe sobre o Projeto Mediação Escolar e Comunitária, na rede estadual de ensino de São Paulo, e dá providências correlatas.

SÃO PAULO. Resolução SE $n^{\circ}$ 43, de 28 de setembro de 2017 - Dispõe sobre a consolidação das diretrizes e procedimentos do Programa Escola da Família e dá providências correlatas. FUNDAÇ̃̃O PARA O DESENVOLVIMENTO DA EDUCACÃ̃O. Disponível em: $\leq$ http://escoladafamilia.fde.sp.gov.br/>. Acesso em 06/07/18

SÃO PAULO (Estado). Secretaria da Educação. Normas gerais de conduta escolar: sistema de proteção escolar. São Paulo: SEESP, 2009.

SÃO PAULO. Tutorial de Recursos Humanos Programa de Ensino Integral - Governo do Estado de São Paulo, 2012

SHOR, Ira, FREIRE, Paulo. Medo e Ousadia - O cotidiano do professor. tradução de Adriana Lopez; revisão técnica de Lólio Lourenço de Oliveira. - Rio de Janeiro: Paz e Terra, 1986.

ZEHR, Howard. Justiça Restaurativa. Tradução de Tônia Van Acker. São Paulo: Palas Athena, 2012.

ZEHR, Howard. Trocando as lentes: um novo foco sobre o crime e a justiça. Tradução de Tonia Van Acker. São Paulo: Palas Athena, 2008.

Recebido em: 01 abr. 2019 / Aprovado em: 02 jul. 2019

\section{$\underline{\text { Cite como }}$}

SANTOS, Eduardo; SANTOS, Sara Xavier dos. Violências escolares e justiça restaurativa na escola básica estadual de são paulo na visão dos professores - o papel do diálogo.

Dialogia, São Paulo, n. 32, p. 136-164, maio/ago. 2019. Disponível em: https://doi.org/10.5585/Dialogia.n32.14352. 